\title{
Results of engineless studies of power plant supports for machine-tractor units operation
}

\author{
N. M. Egorov, F. Kh. Khaliullin*, S. M. Yakhin, and I. G. Galiev
}

Kazan State Agrarian University, 420015 Kazan, Russia

\begin{abstract}
When using a machine-tractor unit, external conditions of its operation change in a wide range. It results in frequent changes in the parameters of speed and load modes of its power plant. Resulting vibrations and oscillations in addition to discomfort and excessive loads on components and mechanisms of the power plant also cause fuel overspending and power losses. To reduce negative vibration impact on effective performance of the power plant creation of supports with adjustable characteristics is suggested. Both internal unbalance of the power plant itself and external influence of variable moment of resistance and impulses of supports themselves are considered perturbing moments. Changes in rigidity and damping coefficients of relevant supports can reduce the amplitude of oscillations of the power plant in variable operating modes, which will improve its utilization indicators.
\end{abstract}

\section{Introduction}

In operational conditions, the operation of power plants of machine-tractor units (MTU) is followed by changes in speed and load modes of operation. Both external and internal factors are the sources of such changes [1, 2]. Internal factors include unbalanced forces and moments of inertia of reciprocating and rotating moving masses, technological and structural unbalance of the engine and various technical conditions of its cylinders; and external factors include the changeable nature of the surface pattern, treated soil or parameters of technological process [3].

The level of vibration load of MTU and selfpropelled vehicles depends on a number of different reasons, among which the following ones are determining: design and mode of operation of the power plant, number, location and parameters of power unit (PU) supports, suspension structure, type of tires used, characteristics of micro profile of road surface, fuel used, etc. [4].

The power unit is the main source of machine vibration [5]. Type of vibration transmitted through PU supports is determined by motor type. The greatest vibrations correspond to in-line engines ranging from two-, four-, five-cylinder engines to a V-shaped twelvecylinder engine [6]. For the most effective vibration balancing, it is necessary to carry out a thorough feasibility evaluation of the engine design as early as at the stage of preliminary design, taking into account modes and conditions of its operation, as well as the type of MTU on which it will be installed.

In order to ensure a high level of vibration reliability, it is necessary to choose engine configuration in which the operating vibration excitations would be minimal. At an increased speed of rotation of crankshaft, vibrations are transmitted through PU supports, caused mainly by an imbalance and unbalanced forces and moments of the engine. Reducing friction in kinematic pairs, lower engine crankshaft speeds by 100 min- 1 reduces, as a rule, the noise of diesel engine by $1 \mathrm{~dB}$.

The level of vibration and structural noise are also affected by engine exhaust [7]. The use of supports and suspensions of increased rigidity, as well as mounting directly to the base of body lead to an increase in vibration effect of engine exhaust. Experiments show that noise level can increase by 5-8 dB.

Great concern for the environmental factor during MTU operation led to the search for more environmentally friendly fuels, which prompted the study of influence of various types of fuel on PU vibration level. Experiments show that when using biodiesel instead of pure diesel fuel, there is a decrease in vibration component, which may be associated with a lower cetane number of diesel fuel compared to biodiesel [8]. A set of methods and means to reduce harmful effects of vibration on the human body, devices and various mechanisms is called vibration protection. Vibration protection is performed by the following key methods [9]:

1. Decrease in the level of mechanical impact generated by the source - reduction of vibratory activity of the source; use of vibration damping and soundabsorbing material coatings to reduce spread and radiation by surface structure of spatial vibration due to dissipation of energy of mechanical oscillations internal protection;

2. Attaching to the protected object of an additional mechanical system that changes the nature of its

\footnotetext{
Corresponding author: khaliullin_kgau_taeu@mail.ru
} 
oscillations. This method is called dynamic vibration damping, dynamic vibration dampers act as an additional system;

3. Using an additional source of vibration, with the same amplitude as the source, but the opposite in phase active vibration damping;

4. Installation between the object and vibration source of an additional system that protects the object from vibration impact created by the source. This method of protection is called vibration isolation, and devices installed between the object and vibration source - vibration isolators.

Vibration protection in MTU operating conditions can be performed in one or more of the ways listed above. If the object of protection is exposed to periodic disturbances, then first of all, it is essential to eliminate or reduce their action in the source itself.

For example, if inertia forces from unbalanced parts are vibration source, it is possible to reduce vibration by carrying out appropriate balancing work. In engines, it is also possible to achieve some reduction of vibration by optimizing the combustion process by changing the ignition moment of fuel mixture in cylinders. Vibration damping coatings can be divided into hard, soft, reinforced and combined coatings by the nature that determines the absorption of vibration.

At low frequencies, hard coatings are most effective; in high-frequency areas, their effectiveness is not as high. However, vibration isolation of oscillation source is the most widely used method. In a simplified way, this method can be represented as a mass that is mounted on a spring and a damping element. In such a system with a vibration isolator, only part of the work of external force is spent on changing the kinetic energy. Part of this work goes into potential energy of the spring, and part of it goes into heat and is dissipated by damping element [10].

The application of this method of vibration protection makes it possible to reduce dynamic effects created by vibration source, due to dissipation of vibrational energy in vibration isolator. However, there are undesirable phenomena associated with an increase in static displacements of the protected object in relation to the source, and there is also an increase in the amplitude of relative oscillations in low-frequency and shock disturbances. For this reason, the use of vibration isolators needs the search for compromise solutions that meet various requirements.

To reduce the negative impact of vibrations and oscillations of the engine frame on operation of the machine-tractor unit, it is necessary to select parameters of supports of power plants so that they could absorb the energy of these oscillations with maximum efficiency [11].

\section{Status of the issue}

Currently existing methods for designing parameters of power plant supports are based on the provisions outlined in works [12]. According to the recommendations the following conditions can be chosen:

1) frequency range of disturbing factors is determined according to the value of reference frequency and cutoff frequency after their harmonic analysis;

2) rigidness of the support is selected based on amplitude-frequency characteristics of the power unit and rate of its permissible value;

3) damping characteristics of supports are determined by the decrement of damping oscillations of the power unit at main frequencies of disturbing factors;

4) selected parameters of power unit supports are influenced by its mass and overall dimensions and installation scheme of these supports;

5) support must create conditions for reliable operation of the engine under the influence of continuous impact of various factors that appear during its operation, when the engine is affected by torque, unbalanced forces and moments of inertia of reciprocating and rotational movement of nodes and parts;

6) support must accept the static load of created PU. Since rubber supports are widely used in the structure as a support for PU of MTU, their compression by more than $20 \%$ of the initial height can lead to a significant decrease in vibration-insulating properties of rubber. Therefore, when calculating PU support, it should be considered that when its weight is applied, rubber should not be compressed by more than $15 \%$ of its initial height.

However, the proposed method of design of supports does not consider variability of parameters of disturbing factors of both external and internal origin, which leads to a decrease in their performance beyond a fairly narrow, selected range.

Therefore, there is a need to design supports for power plants with variable characteristics [13] and task of this paper is to assess the impact of rigidity and damping coefficient of supports on the parameters of power unit oscillatory movement. Characteristics of supports should be different for different oscillation frequencies: at low frequencies up to $20 \mathrm{~Hz}$ and an amplitude of $0.3 \ldots 15 \mathrm{~mm}$, the support should provide a more rigid characteristic and strong damping, and at high frequencies (acoustic oscillations) oscillations with a frequency of 20 to $200 \mathrm{~Hz}$ and an amplitude of $0.05 \ldots 0.15 \mathrm{~mm}$, the support should have low rigidity and weak damping.

The purpose of this paper is to determine the degree of influence of parameters of power plants supports of machine-tractor units on their vibration during operating modes

\section{A proposed solution}

To determine experimentally the nature of influence of studied parameters on the oscillatory movement of the power unit and their permissible ranges of change, a laboratory unit was created [14]. The unit for engineless study (figure 1) consists of mechanical inertial vibration stand for test, a frequency converter, sensors, an analogto-digital converter, and a computer. 
Vibration stand for test (figure 2) consists of base 1 and a movable part. Base consists of three equidistant racks, which also serve as guides for movable part of stand for test. Racks are connected to each other from the bottom and top to ensure a rigid structure. Movable part of the stand for test consists of three platforms separated from each other by four racks. Six roller supports 4 are attached to movable part, three at the bottom and top, they roll along the guides of base of stand for test and exclude horizontal movement of movable part, thus ensuring movement strictly in vertical direction. Elastic element 12 is installed under movable part of stand for test. On the lower platform of stand for test there is three-phase asynchronous drive motor 3, as well as a speed sensor, which is optical slot sensor 10 in conjunction with driving disk 9 mounted on the shaft of electric motor 3.

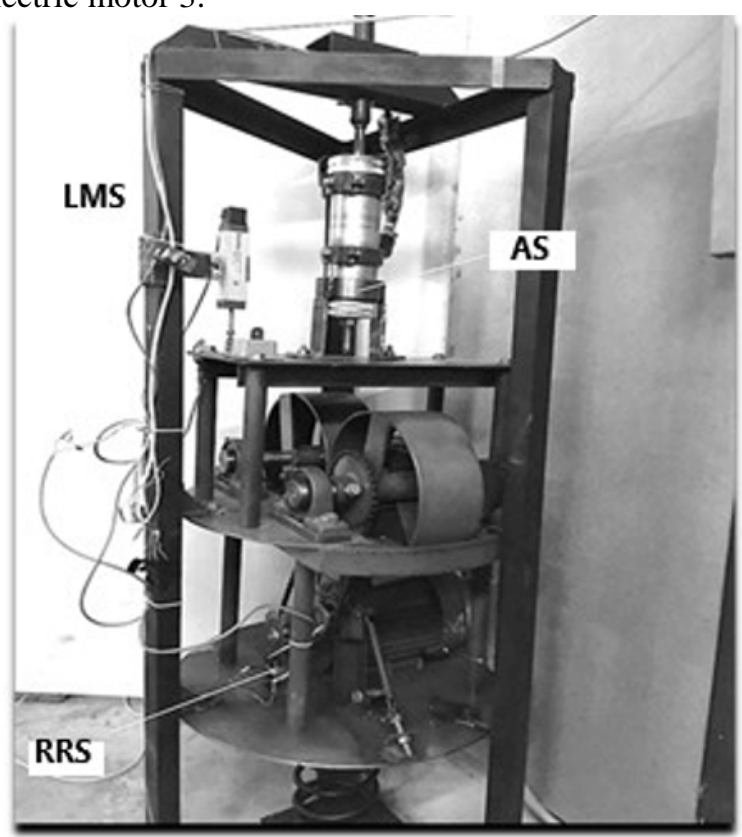

Fig. 1. Vibration stand for test: AS - adaptive support (experimental model); LMS - linear movement sensor; RRS revolution rate sensor

Drive sprocket on electric motor 3 transmits torque through the chain to driven sprocket 8 , which is rigidly attached to one of two shafts. Shafts are located parallel to each other and rotate on housing bearings 7 fixed to the second platform. One drum 5 is mounted and fixed on each shaft. Inside drums there are removable loads 6 , the number of which can be changed. Accordingly, drums act as eccentrics. Torque from electric motor 3 is transmitted through the chain and sprockets to shaft and through a block of four identical gears 19 (figure 3.5, figure 3 in Annex A) transmits to the second shaft. Thus, drums 5 are driven in a rotational motion, and the rotation occurs in different directions.

Eccentrics on two shafts are installed in such a way that loads of two drums 5 rotate symmetrically relative to conventional central axis (vertical) of the stand for test, so that the tilting component of two eccentrics extinguish each other due to different directions, and the vertical component is summed up and creates oscillations of movable part of the stand for test only along the vertical axis (figure 3). Test device 17 is installed on upper platform 2 .

Acceleration sensor 19 is installed on the upper platform. On the upper part of the stand for test there is a screw type base for fixing the device under analysis. Due to the screw design, the upper support is adjustable in height. It serves both for fixing and stopping the device, and for creating a pre-static load.

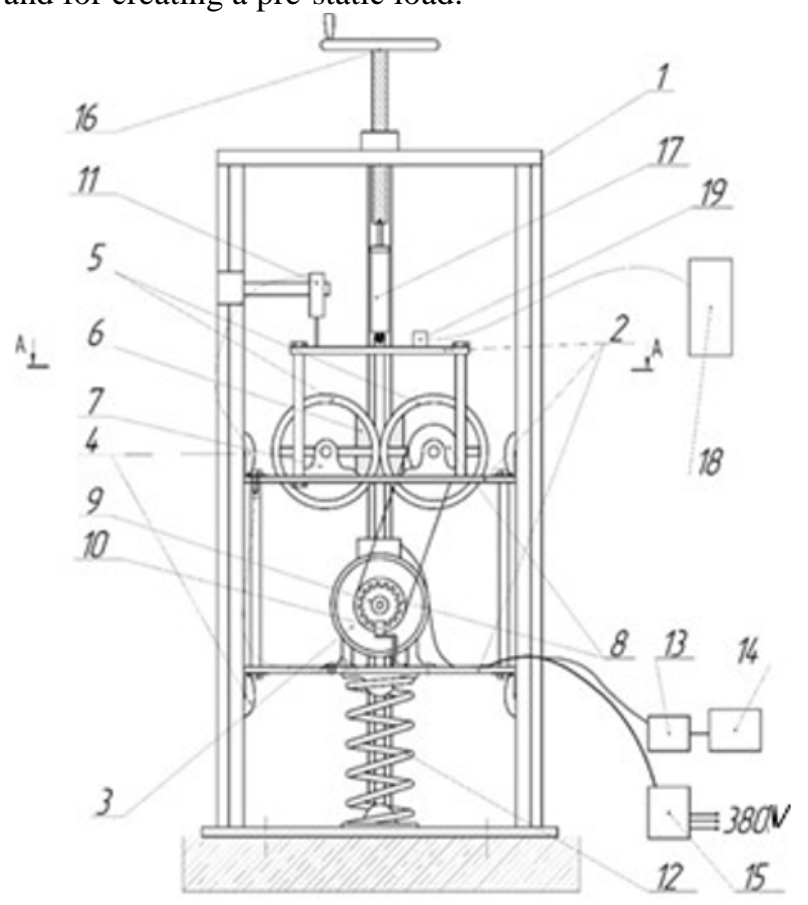

Fig. 2. General diagram of vibration stand for test: 1-base, 2lower, middle and upper platforms, 3-electric motor, 4-support rollers, 5-drums, 6-load, 7-bearing units, 8-master and driven sprockets, 9-driving disk, 10-optical slot sensor, 11-linear displacement sensor, 12-spring, 13-analog-to-digital converter, 14-computer, 15-three-phase frequency converter, 16-screw type base, 17-test device, 18-noise meter-vibrometer, 19accelerometer.

For an engineless experiment on the developed unit, the parameters of D-243 engine support installed on MTZ82 tractor were selected, the parameters of which are shown in table 1 and table 2:

The missing design parameters were selected based on recommendations of literature sources [15-18].

A variant of using power plant supports with different characteristics was considered [19]: rigidity of power unit support $m_{p}=250 \mathrm{kN} / \mathrm{m}$ (support 1 ); $m_{p}=350$ $\mathrm{kN} / \mathrm{m}$ (support 2).

Table 1. Rigidity of supports of power unit

\begin{tabular}{|l|c|c|}
\hline $\begin{array}{l}\text { Name of } \\
\text { flexible element }\end{array}$ & Designation & $\begin{array}{l}\text { Rigidity, } \\
\mathrm{kN} / \mathrm{m}\end{array}$ \\
\hline $\begin{array}{l}\text { Factory-supplied support, } \\
\text { new }\end{array}$ & $\mathrm{F}_{0}$ & 570 \\
\hline $\begin{array}{l}\text { Factory-supplied support, } \\
\text { with average wear value }\end{array}$ & $\mathrm{F}_{1}$ & 380 \\
\hline $\begin{array}{l}\text { Factory-supplied support, } \\
\text { worn out }\end{array}$ & $\mathrm{F}_{2}$ & 320 \\
\hline Rigid spring & $\mathrm{RS}$ & 740 \\
\hline Semi-rigid spring & $\mathrm{SRS}$ & 250 \\
\hline Flexible spring & $\mathrm{FS}$ & 150 \\
\hline
\end{tabular}


Table 2. Support damping coefficients

\begin{tabular}{|c|c|c|}
\hline $\begin{array}{l}\text { Flow throttle } \\
\text { cross section }\end{array}$ & Designation & $\begin{array}{l}\text { Degree of } \\
\text { damping }\end{array}$ \\
\hline Hollow support & D0 & $25 \%$ \\
\hline $2 \mathrm{~mm}$ & D4 & $100 \%$ \\
\hline $4 \mathrm{~mm}$ & D4 & $95 \%$ \\
\hline $6 \mathrm{~mm}$ & D6 & $90 \%$ \\
\hline $8 \mathrm{~mm}$ & D8 & $85 \%$ \\
\hline $10 \mathrm{~mm}$ & D10 & $65 \%$ \\
\hline $12 \mathrm{~mm}$ & D12 & $50 \%$ \\
\hline
\end{tabular}

Figure 3 shows amplitude-frequency response of an adaptive support with various elastic-damping characteristics. First of all, we can see from the histogram that the response amplitude when testing an adaptive support with different characteristics has a difference from a few tenths of $\mathrm{mm}$ to several $\mathrm{mm}$. The greatest variation in readings is observed in the lowfrequency range. The dotted line indicates optimal amplitude-frequency response that can be achieved using this adaptive support under specified conditions and automatic control.

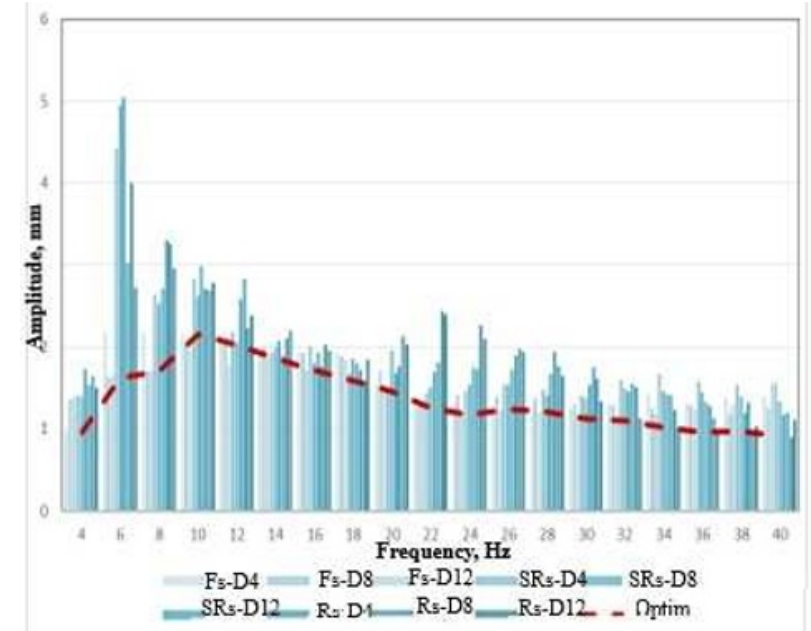

Fig. 3. Amplitude-frequency response of an adaptive support with different characteristics

Adaptive support units with flexible springs have proved to be the most effective in reducing oscillations at low frequencies (figure 4). This is due to the fact that semi-rigidity of springs does not significantly affect the source of oscillations, and the reduction of vibration occurs mainly due to viscous friction of liquid in throttling element of the support. However, at higher frequencies, the adaptive support with a flexible spring shows itself a little worse than other options.

When studying the effectiveness of an adaptive support with semi-rigid springs and different throttles (figure 5), the greatest amplitude of oscillations was observed at low frequencies. At first, this fact seemed strange, but later it was found that semi-rigid springs used in research have the closest rigidity to the spring on which the movable part of the vibration stand for test is installed, compared with flexible and rigid springs, which indicates the coincidence of own frequencies.

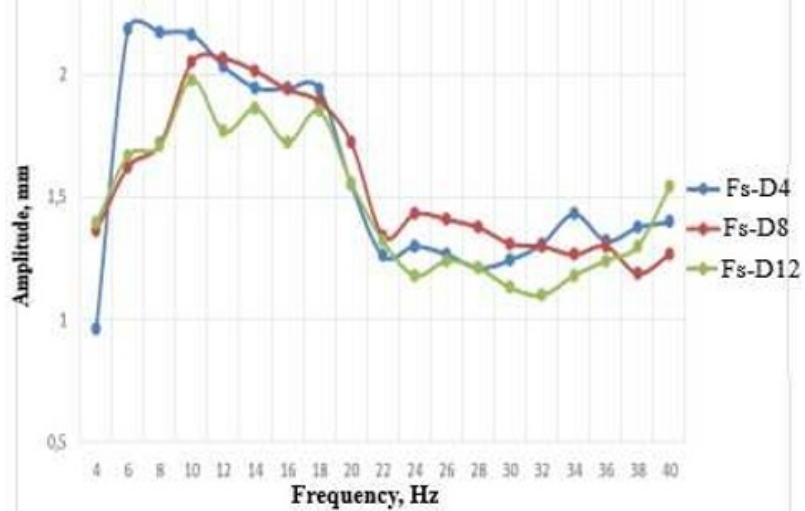

Fig 4. Amplitude-frequency response of an adaptive support with a flexible spring and different throttles

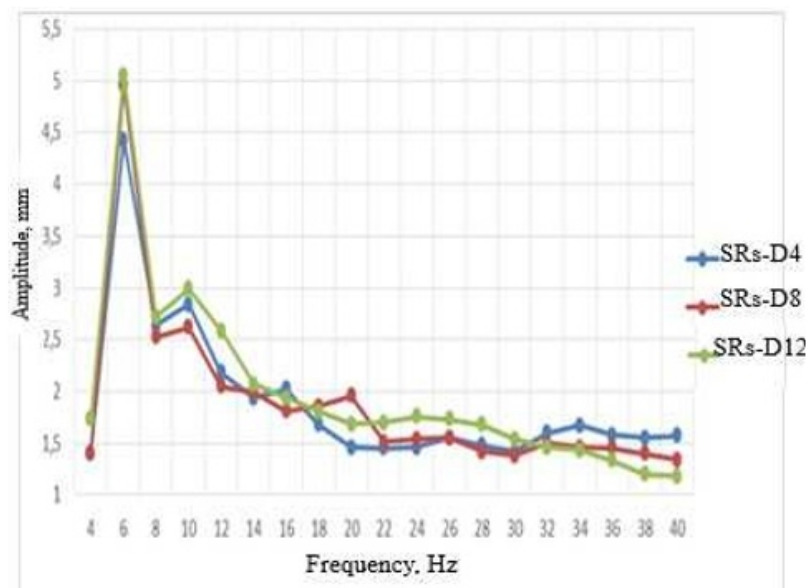

Fig. 5. Amplitude-frequency response of an adaptive support with a semi-rigid spring and different throttles

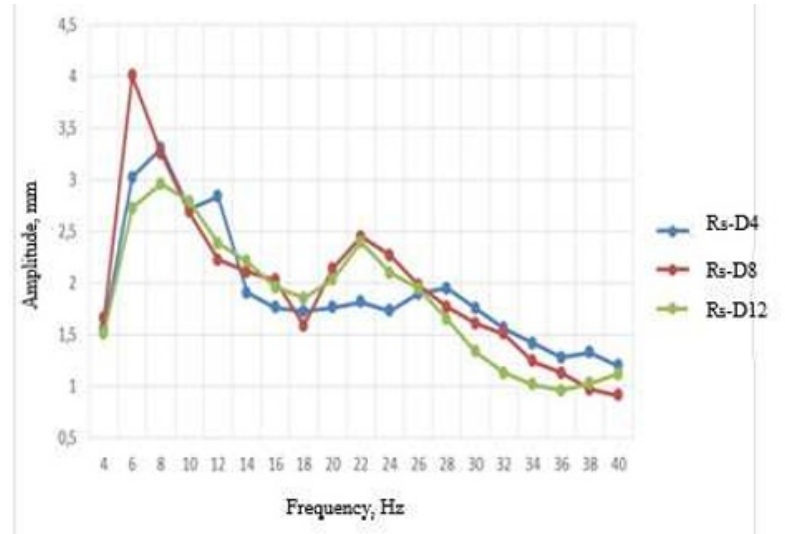

Fig. 6. Amplitude-frequency response of an adaptive support with a rigid spring and different throttles

Thus, potential energy of compressed spring during oscillations went from one spring to another with less losses than in other support units, that in addition to the source of oscillations, which continues to work, leads to an increase in the amplitude at a certain frequency. Moreover, this increase in amplitude is observed with all three throttling elements at the same frequency having a clear peak on the diagram, and the amplitudes differ only by fractions of $\mathrm{mm}$. At higher frequencies, this phenomenon is not observed, and in a certain frequency 
range, the support shows the most effective vibration isolation.

\section{Conclusion}

When conducting studies of an adaptive support with rigid springs, a decrease in the amplitude is observed in comparison with the previous studies of a support with semi-rigid springs. There is also a slight shift of peaks towards higher frequencies, with the diagrams having a flatter shape. The largest difference in amplitudes when using throttling elements of different flow cross-sections is $1 \mathrm{~mm}$.

\section{References}

1. J.P. Wect, Hydraulically-damped engine-mounting, Automotive Engineer, 12(1), 17-19 (1987)

2. N.M. Egorov, F.K. Khalyullin, Stand for test of support in structure of suspension of power unit, in: Mat. of I Int. Sci. and Prac. Conf. dedicated to the memory of Professor A.K. Yuldashev: Dynamics of mechanical systems (Kazan, 5-6 April 2018)

3. D. Dodtibacher, Rechnerische Ermittlung des Schwingverhaltens des elastisch ge-lagerten Motors im Pkm, Automobil-Indastrie, 1, 57-61 (1982)

4. E. Erdiwansyah, Sh. Sani, R. Mamat et al., Vibration Analysis of the Engine Using Biofuel Blends Vibration Analysis of the Engine Using Biofuel Blends: A Review, MATEC Web of Conferences, 225, 01010 (2018)

5. I. Gravalos, D. Moshou, T. Gialamas et al., Vibration Effects on Spark Ignition Engine Fuelled with Methanol and Ethanol Gasoline Blends, J. of Agricultural Machinery Science, 7(4), 367-372 (2011)

6. B. Challen, R. Baranescu, Diesel Engine Reference Book, $2^{\text {nd }}$ ed. (SAE Inc., Great Britain, 1999) 682 p.

7. A.P. Okunev, Choice of rational characteristics of power unit supports of a front-wheel-drive passenger car: candidate dissertation (2010)

8. O.G. Mehmet, B. Burak, K. Necmettin, Modelling and Vibration Analysis of Powertrain System, Int. J. of Automotive Science and Technology, 2(1), 17-25 (2018)

9. V.K. Astashev, V.I. Babitsky, I.I. Bikhovsky, I.I. Wolfson, Vibration in technology, in 6 volumes:
Vol. 6. Vibration and shock protection (Mechanical Engineering, Moscow, 1981) 456 p.

10 A.V. Vasilyev, Features of reducing the vibration of machines in their design and operation, in: Proc. of $I V$ int. sci. and tech. conf. "Thermophysical and technological aspects of improving the efficiency of machine-building production" (Tolyatti State University Press, 2015)

11. F.Kh. Khaliullin, J.K. Aladashvili, A.A. Nurmiev, G.V. Pikmullin, S.A. Sinitsky, Determination of statistical data of conditional probabilities of the technical condition of internal combustion engines when compiling the Bayes diagnostic table, IOP Conference Series: Materials Science and Engineering, 635, 012017 (2019) doi:10.1088/1757899X/635/1/012017

12. Guidance document RD 37.001.008-83 Vibration of power units of the car. Measurement methods. Recommended acceptable values. Official publication (NAMI, Moscow, 1983) $17 \mathrm{p}$.

13. W.S. Flower, Understanding Hudraulic Mounts for Improved Vehicle Noise, Vibration and Ride Qualitits, SAE paper, No. 850975, pp. 123-132 (1985)

14. N.M. Egorov, F.K. Khalyullin, Adaptive support of power units, in: Mat. of I Int. sci. and pract. conf. dedicated to the memory of Professor A.K. Yuldashev: Dynamics of mechanical systems (Kazan, 5-6 April 2018)

15. G.M. Kutkov, Tractors and automobiles. Theory and technological properties (KolosS, Moscow, 2004) 504 p.

16. I.P. Ksenevich, V.M. Sharipov, L.Kh. Arustamov et al., Tractors. Design: textbook for university students (Mechanical Engineering, Moscow, 2000) $821 \mathrm{p}$.

17. G.K. Kaptyushin, S.P. Bazhenov, Design, fundamentals of theory, calculation and testing of tractors (Agropromizdat, Moscow, 1990) $511 \mathrm{p}$.

18. N.V. Matyukhov, I.F. Bruenkov, E.A. Bomberov et al., Tractors "Belorus" MTZ-80, MTZ-80L, MTZ-82, MTZ-82L: Tech. description and instruction of operation, $2^{\text {nd }}$ ed. (Uradjay, Minsk, 1981) 352 p.

19. N.M. Egorov, F.K. Khalyullin, Adaptive support of power units, in: Mat. of I Int. sci. and pract. conf. dedicated to the memory of Professor A.K. Yuldashev: Dynamics of mechanical systems (Kazan, 5-6 April 2018) 